\title{
Landscape-scale variation in coral recruitment in Moorea, French Polynesia
}

\author{
Peter J. Edmunds ${ }^{1 *}$, James J. Leichter ${ }^{2}$, Mehdi Adjeroud ${ }^{3}$ \\ ${ }^{1}$ Department of Biology, California State University, 18111 Nordhoff Street, Northridge, California 91330-8303, USA \\ ${ }^{2}$ Scripps Institute of Oceanography - 0277, University of California at San Diego, 9500 Gilman Drive, La Jolla, \\ California 92093, USA \\ ${ }^{3}$ Institut de Recherche pour le Développement, U 227 COREUS 2, Centre de Biologie et d'Ecologie Tropicale et \\ Méditerranéenne, Université de Perpignan Via Domitia, 66860 Perpignan, France
}

\begin{abstract}
In this study, we describe spatio-temporal variation in coral recruitment in the back reef of Moorea, French Polynesia, and explore the extent to which it is associated with community structure, seawater temperature, and wave regimes. Recruitment was assessed with settlement tiles deployed at 10 sites on the north, southeast, and southwest shores and sampled every 5 to 7 mo from 2005 to 2007. Temperature and waves were measured using thermistors and pressure sensors, and community structure was assessed using in situ surveys. Mean recruitment varied from 0 to 6 recruits tile ${ }^{-1}\left(510 \mathrm{~cm}^{2}\right)$ and was generally greater in the second compared to the first year of the study. Recruitment varied among sites, and this variation was similar between years but differed among sampling periods: acroporids were common on the southwest shore between January and September, but rare from September to January; poritids were common on the north shore between September and January, but rare on the southwest shore from January to September; and pocilloporids were found all year, but at slightly elevated densities between January and September. The mean daily seawater temperature, and the daily range, varied among sites, but neither was closely related to coral recruitment, and both were of biologically small magnitudes. The coral community structure also varied among sites, but likewise, was not associated with coral recruitment. In contrast, outer reef wave energy exposure, which likely played an important role in driving cross-reef transport of seawater into the lagoon, differed between shores and seasons in a pattern consistent with the variation in coral recruitment in the back reef. We hypothesize that coral recruitment in the back reef of Moorea is influenced by the interaction of seasonal variation in wave exposure, family-level differences in coral reproductive timing, and the spatial distribution of adult corals.
\end{abstract}

KEY WORDS: Scleractinia $\cdot$ Settlement $\cdot$ Recruitment $\cdot$ Moorea $\cdot$ Spatial $\cdot$ Temporal Resale or republication not permitted without written consent of the publisher

\section{INTRODUCTION}

The recruitment of scleractinian corals onto tropical reefs is a critical process, maintaining coral populations and facilitating recovery following disturbance (Done et al. 1991, Dunstan \& Johnson 1998, Vermeij \& Sandin 2008). In most cases, coral recruits have sexual origins in brooding or broadcasting life-history strategies (but see Yeoh \& Dai 2010), which give rise to free swimming planula larvae with planktonic phases of widely varying durations (Richmond 1987, Harrison \&
Wallace 1990, Miller \& Mundy 2003, Graham et al 2008), potentially in excess of 1 yr (Vermeij et al. 2009). Brooded larvae can be competent to settle within minutes of release (Best \& Resing 1987, Carlon \& Olson 1993), but can persist for months in a planktonic phase (Richmond 1987, Graham et al. 2008). Larvae arising from broadcast-spawned gametes typically require hours to days before they are competent to settle (Miller \& Mundy 2003, Vermeij et al. 2006), but can thereafter survive in the plankton for months (Graham et al. 2008). 
For more than 2 decades, scientific opinion regarding the extent to which coral populations are open or closed (sensu Caley et al. 1996) has varied, with some studies supporting the notion that they are relatively closed and self-seeded (Sammarco \& Andrews 1988, Black 1993), and others demonstrating that they are more open and affected by recruits from distant locations (Fisk \& Harriott 1990, Hughes et al. 1999). The consensus opinion over much of this time favored the open construct as characteristic of most scleractinian populations (Caley et al. 1996), based in part on the observation that the majority are broadcast spawners (Harrison \& Wallace 1990). A similar bias favoring wide acceptance of the open population model has influenced studies of most marine species with pelagic larvae (Levin 2006, Cowen \& Sponaugle 2009), but recently there has been renewed interest in the possibility that populations can be remarkably closed even though they have dispersive larvae (Levin 2006, Cowen \& Sponaugle 2009, Jones et al. 2009). This resurgence of interest in the 'closed population model' has been fueled by examples of limited dispersal for a broad range of taxa (Cowen \& Sponaugle 2009), including scleractinian corals (Vermeij 2005, van Oppen et al. 2008, Gilmour et al. 2009, Underwood et al. 2009). It now seems much clearer than was recently the case that populations of many marine organisms occupy a gradient from fully open to fully closed, with their position on this gradient determined by a complex assortment of biological and physical processes (Cowen \& Sponaugle 2009, Jones et al. 2009).

It is not surprising, therefore, that conflicting results have been obtained for tropical scleractinians when associations between densities of early life-stage corals and contemporaneous adult colonies have been sought, with some studies reporting a correlation between the 2 (Chiappone \& Sullivan 1996, Vermeij \& Sandin 2008) and others discovering a disconnect between them (Bak \& Engel 1979, Edmunds 2000). Since these (and similar) studies often define early life stages broadly (e.g. as juvenile colonies), most cannot resolve the effects of settlement and post-settlement success in determining population structure. In one exception to this generalization, Penin et al. (2010) defined small colonies $\leq 3$ mo old on settlement tiles as coral recruits, colonies $1-5 \mathrm{~cm}$ in diameter as juveniles, and colonies $>5 \mathrm{~cm}$ diameter as adults, and tested whether the density and taxonomic composition of the 3 life stages were associated on the outer reefs of Moorea, French Polynesia. Their analyses showed significant relationships between adults and juveniles for all corals combined, as well as for the acroporids and poritids (but not the pocilloporids), whereas adults and recruits were unrelated for all corals combined as well as for pocilloporids, but were related for acroporids and poritids; the relative abundance of coral families differed between recruits and adults, but not between juveniles and adults (Penin et al. 2010). The results of Penin et al. (2010) underscore the potential role of high post-settlement mortality (see also Dunstan \& Johnson 1998) in decoupling the dynamics of adult corals and recruiting life stages and, at least for the outer reefs of Moorea, the strong role that fish predation might play in driving these mortality effects.

The aforementioned studies illustrate the challenges of developing biological interpretations of evidence suggesting that densities of adult and early-life stage corals are (or are not) related. Additionally, they emphasize how little is known about the interactions between corals and their environment that place their populations on the gradient between open and closed (Cowen \& Sponaugle 2009, Jones et al. 2009). Many of the least known factors affecting coral recruitment involve biophysical coupling, such as the ways in which physical conditions affect coral reproduction (van Woesik et al. 2006, Albright et al. 2008, Randall \& Szmant 2009, van Woesik 2010) and the relationship between larval supply and local recruitment. Aspects of these relationships are coming to light, for example the effects of high temperatures in preventing gametogenesis (Szmant \& Gassman 1990) and affecting fertilization (Negri et al. 2007), the effects of subtle rises in temperature in accelerating reproductive phenology (TY Fan pers. comm.) and shortening larval duration (Edmunds et al. 2001), the conditions under which the fecundity of adult corals is associated with local coral recruitment (Hughes et al. 1999, 2000), and the role of hydrographic conditions in modulating larval dispersal (Sammarco \& Andrews 1988, Underwood et al. 2009).

Seawater temperature and flow regime are 2 physical factors that strongly affect coral recruitment (Sammarco \& Andrews 1988, Harrison \& Wallace 1990, Adjeroud et al. 2007). Independent of the influences of temperature on gametogenesis and fertilization (Szmant \& Gassman 1990, Negri et al. 2007), temperature also affects larval development (Edmunds et al. 2001, Putnam et al. 2008) and perhaps substrate selection (Putnam et al. 2008). Coral larvae exposed to warmer seawater develop more rapidly than those at a lower temperature, and settle with a potentially impaired capacity to select suitable settlement surfaces (Edmunds et al. 2001, Putnam et al. 2008). The effects of temperature can also interact with water flow; for example, the effects of high temperature in bays and lagoons are accentuated by reduced water motion. Conversely, increased water transport can reduce the time that larvae are exposed to perturbed thermal regimes and accelerate the rate of delivery of larvae to suitable settlement locations (Cowen 2002). Since biophysical coupling between coral recruitment and both temperature and flow can only function if coral 
larvae are present, at some spatial scale the coupling must also be affected by benthic community structure and the reproductive output of adult corals at a given location in space and time.

The objectives of this study were to explore spatiotemporal variation in the recruitment of corals in the back reef of Moorea and test the extent to which such variability is associated with physical and biological features of the environment. The back reef of Moorea provides an interesting habitat in which to explore such relationships because the coral community occurs as discrete patches within an extensive habitat occupying $>50 \mathrm{~km}$ of coast and extending to $1 \mathrm{~km}$ from the shore. The back reef wraps around the island and creates a semi-enclosed waterway that is blocked for a few $\mathrm{km}$ at the island's northeast corner (Fig. 1). The north shore is impacted by large waves, which drive cross-reef transport in the austral summer (Hench et al. 2008). The southeast and southwest shores are exposed to waves that drive cross-reef transport throughout the year, and they experience especially large waves in the austral winter. Here we describe (1) coral recruitment to settlement tiles deployed for $\sim 6$ mo intervals over a 2 yr period at multiple sites within the back reef, (2) differences in coral community structure and seawater temperature among these sites, and (3) seasonal variation in wave energy around the island.

\section{MATERIALS AND METHODS}

General design. To quantify spatio-temporal variation in coral recruitment and evaluate its relationship to biological and physical conditions, 10 sites were

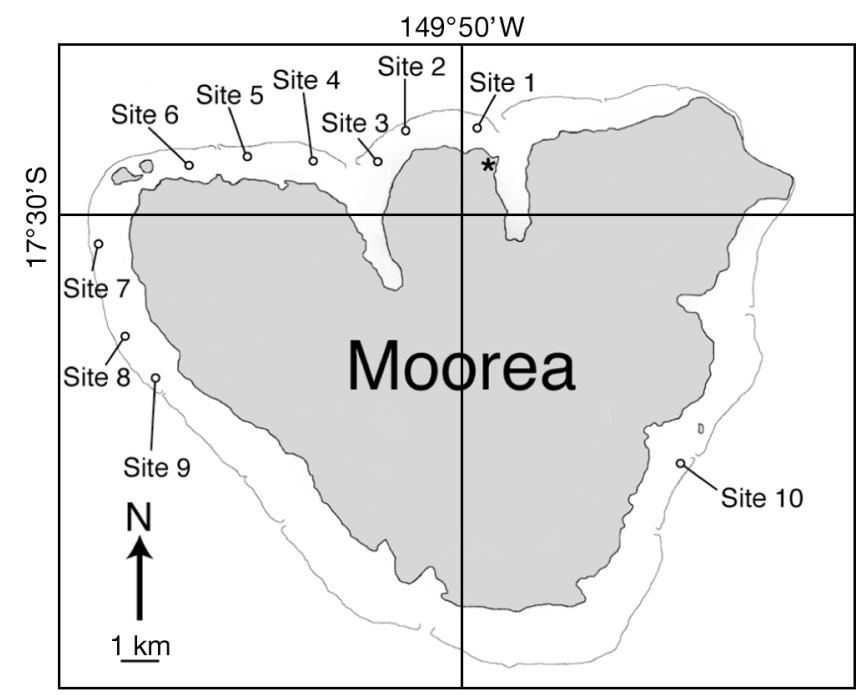

Fig. 1. Moorea, French Polynesia: the 10 study sites within the back reef. Thin outer line: reef crest, *: Richard B. Gump South Pacific Research Station selected haphazardly in the back reef of Moorea (Fig. 1). Six were located on the north shore, 3 on the southwest shore, and 1 on the southeast shore, together spanning a spatial scale of $\sim 20 \mathrm{~km}$. The sites were at $1.5-2.0 \mathrm{~m}$ depth, $\sim 100-500 \mathrm{~m}$ from the reef crest, and in areas where the benthos consisted of live coral $(<45 \%$ cover in 2007; P. J. Edmunds unpubl. data) and carbonate rock suitable for attaching settlement tiles. These sites were selected, in part, because at times they differed in physical aspects of the environment (i.e. seawater temperature and flow), which was a pattern conducive to correlative tests of the extent to which variation in coral recruitment might be forced by variation in physical factors. As these differences were neither well developed nor fully described when the study began, the sites were considered a random factor in the statistical analysis.

Settlement tiles. Settlement tiles were chosen to evaluate relative rates of coral recruitment among sites and times. While they generate results that differ depending on their composition, texture, and orientation (Harriott \& Fisk 1987, Mundy 2000, Nozawa 2008), they are nevertheless effective for spatio-temporal contrasts of relative rates of recruitment when deployed in a consistent manner (Mundy 2000, Penin et al. 2010); the rates of coral recruitment to artificial settlement tiles are likely to be upwardly biased relative to natural surfaces (Penin et al. 2010). In the present study, settlement tiles were unglazed terracotta, $15 \times 15 \times 1 \mathrm{~cm}$ (i.e. with a combined area of $510 \mathrm{~cm}^{2}$ ), with a smooth upper surface and a lower surface roughened with ribs. Each tile was drilled with a central hole for attachment, seasoned in seawater for several months, and attached to the reef, rough side down, with a stainless steel stud epoxied into reef rock. A nut at the base of the stud elevated the tile above the substratum to form a cryptic habitat $\sim 8 \mathrm{~mm}$ high that is preferred by settling coral larvae (Mundy 2000).

At each site, 15 tiles were installed in an area $\sim 3 \mathrm{~m}$ in diameter, and each tile was treated as an independent replicate. The tiles were first deployed on 12-16 September 2005 and replaced on 20-26 January 2006, 4-11 September 2006, 16-18 January 2007, and 11-16 September 2007 (marked I to V in Fig. 2). On most occasions, tiles were replaced on the same day with new tiles that had been seasoned as described above. At each sampling, tiles were removed from their studs, transported to the lab, cleaned of organic material in bleach, dried, and inspected microscopically $(\sim 100 \times$ magnification) for coral recruits. Coral recruits were scored by location on the tile (upper, lower, and edge surfaces), and identified to family using corallite structure. Three families were identified (Pocilloporidae, Poritidae, and Acroporidae), and unknown recruits were categorized as 'others'. All poritids, acroporids, 

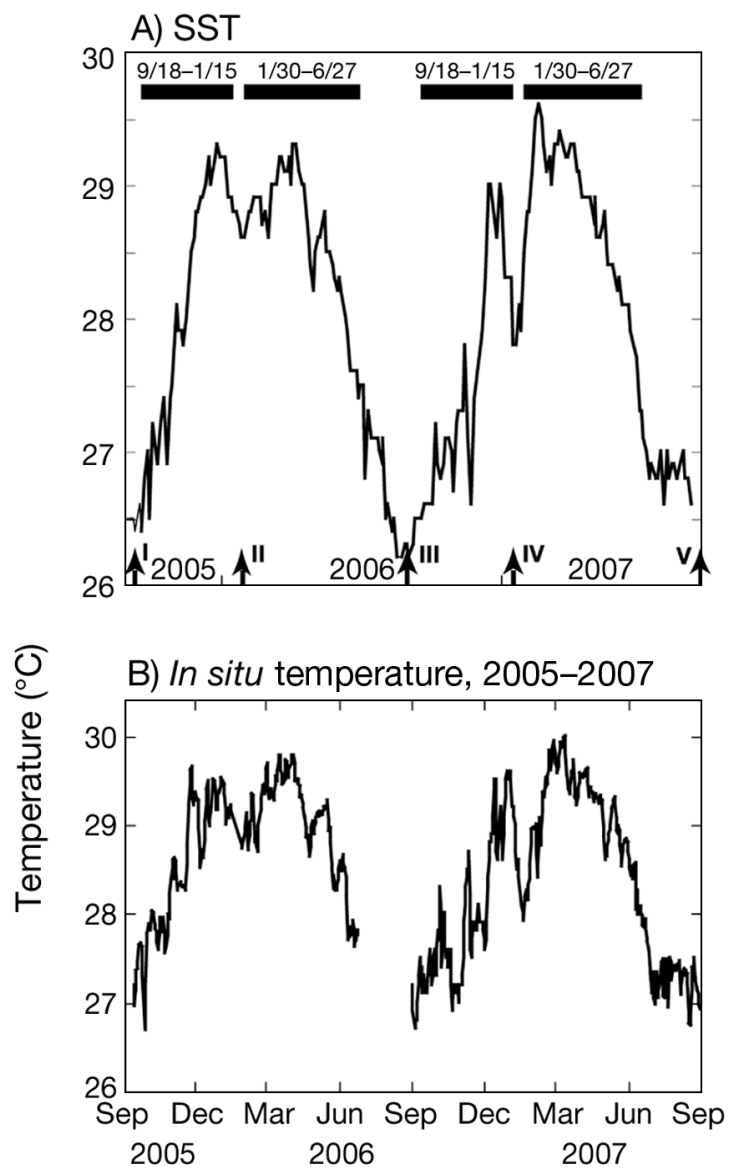

C) In situ temperature over $3 \mathrm{~d}$

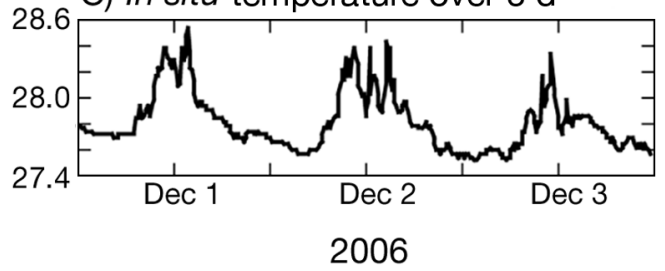

Fig. 2. Seawater temperature around Moorea between 2005 and 2007. (A) Coastal waters sea surface temperature (SST) between August 2005 and September 2007, dates for settlement tiles deployments, recoveries, and analysis (I-V), and periods (black horizontal bars; given as mo/d) when in situ temperature loggers provided a continuous record of seawater temperature. SST was recorded bi-weekly at night with $50 \mathrm{~km}$ resolution using the Advanced Very High Resolution Radiometer (AVHRR) on NOAA's Polar orbiting Environmental Satellites (POES) (http://coralreef watch.noaa.gov). SST provides a context for the analysis of in situ seawater temperature and recruitment in the back reef, and the relationships between the periods of rapid seasonal warming and cooling relative to the deployment periods for the settlement tiles. (B) Representative in situ ( $2 \mathrm{~m}$ depth) seawater temperature at Site 1 for 17 Sep 2005-31 Aug 2007. Data plotted with daily resolution; gap between 27 Jun 2006 and 3 Sep 2006 caused by a logger failure. (C) Representative record of diurnal variation in seawater temperature at Site 1 over $3 \mathrm{~d}$ in Dec 2006; data were recorded every $10 \mathrm{~min}$ starting at $0: 00 \mathrm{~h}$ on 1 Dec 2006 and pocilloporids (except Pocillopora damicornis) for which data are available from Moorea reproduce by broadcast spawning of gametes (Carroll et al. 2006, M. Adjeroud unpubl. data). Once scored, the tiles were soaked in dilute $\mathrm{HCl}$ to remove calcareous taxa and stored underwater in Cook's Bay until installation at a future date.

Community structure. The coral reef community structure at each of the study sites (except Site 10 for logistical reasons) was quantified in September 2008 using quadrats $(0.5 \times 0.5 \mathrm{~m})$ subdivided into 25 equal squares to provide a $4 \%$ resolution for the analysis. At each site, quadrats were positioned at 20 random locations along a $20 \mathrm{~m}$ transect oriented parallel to the reef crest, and the substratum was visually evaluated. The dominant substratum type within each square was scored as scleractinian coral (separated to genus), sand, or a combined category consisting of crustose coralline algae (CCA) and bare space. Macroalgae and algal turf were also scored, but these categories were rarely dominant in the squares $(<2$ and $<17 \%$, respectively), and therefore are not described further. The quantification of coral community structure in 2008 as a means to estimate the coral community structure when the study was completed between 2005 and 2007 (when settlement tiles were deployed) assumes that it did not vary appreciably between 2005 and 2008. This assumption is supported by the absence of broad changes at 4 additional back reef sites on the north and southwest shores of Moorea that have been photographed annually (100 photoquadrats site ${ }^{-1} \mathrm{yr}^{-1}$, of $0.25 \mathrm{~m}^{2}$ each) since 2006 as part of the monitoring at the Moorea Coral Reef Long Term Ecological Research (LTER) site.

The data from the back reef in 2008 were used to describe the community structure at 9 of the 10 study sites, and were also pooled within each shore to describe the cover of Acropora spp., Montipora spp., and Porites spp. (henceforth: Acropora, Montipora, Porites) across the back reef. To obtain comparable data describing the percentage cover of these genera for the outer reef, the results from 2 LTER sites on each shore were averaged by depth (10 and $17 \mathrm{~m}$ ) for 2006 . These data were obtained from photoquadrats $(0.25$ $\mathrm{m}^{2}$ ) that were positioned at fixed locations at each site/depth combination, and analyzed by overlaying the images with a grid of 200 randomly placed dots and counting the dots on each substratum of interest. The photoquadrats were pooled between sites within each depth/shore combination to provide 77 to 80 replicate samples for each depth and shore.

Seawater temperature. Seawater temperature was recorded using Hobo Water Temp Pro loggers (Onset Computer, resolution $\pm 0.2^{\circ} \mathrm{C}$ ) secured in contact with the substratum at the center of each tile cluster. Log- 
gers were inter-calibrated prior to use by recording temperature while bundled together and submerged in the back reef. The mean difference among pairs of loggers was $\leq 0.05^{\circ} \mathrm{C}$ and the temperatures subsequently logged at each site were, therefore, processed without correction for inter-logger variation.

Loggers were wrapped in plastic tape to ease the removal of fouling organisms when they were recovered, and were programmed to sample every $10 \mathrm{~min}$ (first 2 deployments) and at $15 \mathrm{~min}$ intervals on the subsequent 2 deployments. A preliminary experiment in which loggers were deployed in a paired design in sun and shade in the back reef was used to test for solar warming of the instruments. The loggers in the sun differed $<0.14 \pm 0.02^{\circ} \mathrm{C}$ (mean $\pm \mathrm{SE}$, $\mathrm{n}=25$ measurements between $11: 00$ and $13: 00 \mathrm{~h}$ on 13 April 2006) from loggers in the shade, and therefore it is unlikely that solar warming of the instruments biased the temperature records. The loggers were downloaded each time the settlement tiles were replaced, and were redeployed within a few days. The logging durations differed between the two SeptemberJanuary periods (in 2005/06 and 2006/07) and the two January-September periods (in 2006 and 2007), because the more frequent sampling in the first deployments caused the memory to fill and the logging to end prematurely. The longer records were truncated so that the sampling periods were constant in all years (148 d between September and January, and $120 \mathrm{~d}$ between January and June), so that among-site contrasts within each sampling period could be compared equitably (i.e. based on equal sampling) between years.

An initial screening of the temperature records revealed strong diurnal variation and slight differences among sites in daily means (Fig. 2). Temperature records were subsequently analyzed with respect to 2 metrics: (1) daily mean, and (2) daily range.

Wave regime. Continuous wave measurements were made with recording pressure sensors (Seabird Electronics SBE 26+ wave-tide recorders) fixed to the substratum at $10 \mathrm{~m}$ depth on the fore reef at the north, southeast, and southwest shores (LTER Sites 1, 4 and 5). The recorders sampled in a rapid sampling burst mode for 5 min every $2 \mathrm{~h}$, and significant wave height and dominant wave period were recorded for each burst interval. Wave energy flux, an estimate of the kinetic energy per $\mathrm{m}$ of incident wave crest, was calculated as:

$$
P=\rho g^{2} H_{\text {sig }}^{2} T / 64 \pi
$$

where $P$ is wave energy flux $\left(\mathrm{kW} \mathrm{m}^{-1}\right), \rho$ is mean sea water density (assumed to be constant $1028 \mathrm{~kg} \mathrm{~m}^{-3}$ ), $g$ is the acceleration due to gravity $\left(9.8 \mathrm{~m} \mathrm{~s}^{-2}\right), H_{\text {sig }}(\mathrm{m})$ is significant wave height, and $T$ is dominant wave period (s) (Dean \& Dalrymple 1991). Daily averages of $P$ were calculated from the 12 wave measurements of $H_{\text {sig }}$ and $T$ per day. Total wave power values summed over $20 \mathrm{~d}$ following the full moons in September, October, and November in each study year were also calculated. This time period corresponds to known timing of acroporid larval release in Moorea (Carroll et al. 2006).

Statistical analyses. The analysis of recruitment was limited by the small number of recruits, which created departures from the assumptions of parametric statistical procedures. Some of these problems were resolved by pooling among taxa. To test for overall spatiotemporal variation in coral recruitment, the density of recruits (pooled by taxon) was compared among sites, sampling period (September to January, and January to September), and years (2005-06 and 2006-07) using a mixed model, 3-way ANOVA in which sites were treated as a random factor, with periods and years as fixed factors. Sites were rationalized as a random factor as they were selected haphazardly within the lagoon with little a priori expectation that they would differ in specific ways; periods were considered fixed as they were selected, in part, to sample specific periods of coral spawning; years were treated as fixed as 2 consecutive years do not serve effectively as a random sample from a population of years. The densities of recruits per tile were transformed $(\sqrt{ }(x+3 / 8)$; Zar 2010) where needed to satisfy the assumption of normality, and the individual settlement tiles were treated as statistical replicates. Having tested for overall spatiotemporal variation, the densities of recruits were compared by taxon among the sites for each sampling period and for both years. These contrasts were completed with 1-way ANOVAs when the data met the parametric assumptions of these procedures, or with Kruskal-Wallis non-parametric tests when data were not normally distributed. Benthic community structure was compared among sites with 1-way ANOVA with arcsine transformation of the percentage cover data. The assumptions of normality and homoscedasticity for the ANOVA were tested through graphical analyses of residuals.

The mean daily temperature and the daily range in temperature were compared with respect to means and variances among site, but were not compared statistically because daily temperature records are serially autocorrelated and violate the assumption of independence for both parametric and non-parametric procedures. The autocorrelation was statistically significant $(\mathrm{p}<0.05)$ out to a time separation of at least $60 \mathrm{~d}$ (results not shown) and, therefore, it was not feasible to sub-sample the data at the frequency necessary (>60 d) to ensure independence. 


\section{RESULTS}

\section{Recruitment tiles}

Corals recruited to the tiles in all of the sampling periods and were found mostly on the lower surfaces. Of 770 coral recruits found on 636 tiles, $96 \%$ were on the bottom, $4 \%$ on the sides, and $<1 \%$ on top. In most cases, each tile had only a few recruits (and sometimes none), although 1 tile had 22 recruits, and 8 had $\geq 11$ recruits. Over the 24 -mo study, the most common recruits belonged to the families Poritidae (34\% of recruits), Acroporidae (27\%), and Pocilloporidae $(23 \%)$; the remainder $(17 \%)$ was categorized as 'unknown'.

The relative abundance of recruits (pooled over the study) in the 4 taxa varied between sampling periods $\left(2 \times 4\right.$ contingency table, $\left.\chi^{2}=89.562, \mathrm{df}=3, \mathrm{p}<0.001\right)$, largely because relatively few acroporids, but many poritids, recruited between September and January compared to January to September (Fig. 3). The relative abundance of recruits (pooled between sampling periods) in the 4 taxonomic groups was also affected by sampling year $\left(2 \times 4\right.$ contingency table, $\chi^{2}=19.39$, df $=$ $3, \mathrm{p}<0.001$ ), largely because relatively few acroporids were found in 2005/06, but relatively large numbers were found in 2006/07 (Fig. 4).

For all of the corals (pooled among taxa), the density of recruits was affected by the Site $\times$ Sampling period $\times$ Year interaction, as well as the interaction of Site $x$ Year, Year $\times$ Sampling period, and Sampling period $\times$ Site (Table 1). These effects are displayed in Fig. 4, which shows that the density of recruits differed among sites in a pattern that varied between years and sampling periods. For example, the highest density of recruits between September and January occurred at Site 7 in 2005/06 but at Site 5 in 2006/07, and between January and September, the highest density of recruits was found at Site 9 in 2005/06, but Site 7 in 2006/07. The lowest recruitment rates were consistently found at Site 10 on the southeast coast, except between September and January 2005/06 when recruits were absent at Site 1. There were also differences among sites in both sampling periods and both years for poritids $\left(H \geq 20.152, \mathrm{n}=13-15\right.$ tiles site $^{-1}$ period $^{-1}, \mathrm{p} \leq$ 0.017 ), as well as for pocilloporids and acroporids in both periods of 2006/07, and between January and September of $2007\left(H \geq 22.476, \mathrm{n}=13-15\right.$ tiles site $^{-1}$ period $^{-1}, \mathrm{p} \geq 0.007$ ). There were no differences among sites for pocilloporids and acroporids for the September to January period of 2005/06 ( $p \geq 0.232$ ) when recruits of these taxa were rare (Fig. 4).

In general, the pattern of among-site differences varied among taxa, sampling period, and year, although it was not possible to test for interactive effects because the data violated the assumptions of ANOVA. Qualitatively, acroporids were rare between September and January, but were common between January and September when they were found on the southwestern shore in 2006 (Site 9) and 2007 (Site 7). Poritids were common in both sampling periods, but were most abundant on the north shore (Sites 2 to 6) between September and January in 2006/07, and the southwest shore (Sites 8 and 9) between January and September in 2006. Pocilloporids were most common between January and September, with slightly elevated densities at Site 2 in 2006, and at Sites 5 and 7 in 2007, and at Site 7 in 2007 (Fig. 4).

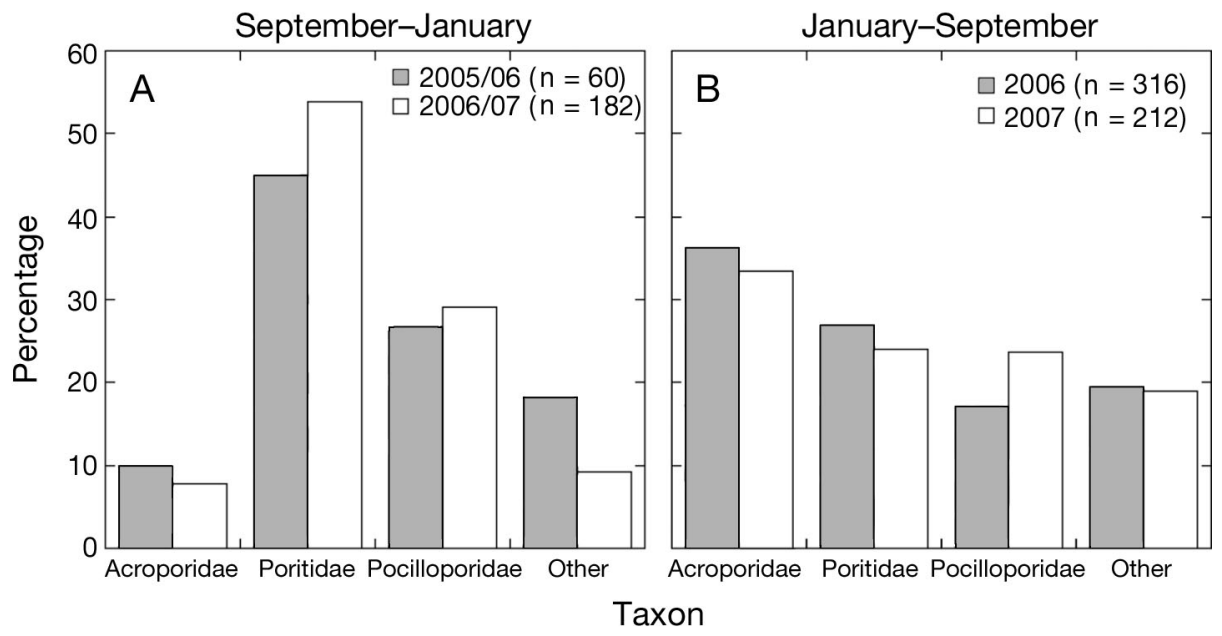

Fig. 3. Relative taxonomic composition (pooled by sites) of coral recruits on settlement tiles (150 tiles period ${ }^{-1}$ ) deployed for 4 periods (A: Sep-Jan, and B: Jan-Sep) over 2 yr (2005/06, grey bars and 2006/07, open bars). Values are for the 3 common coral families, with all other corals placed in 'Other' category. n: total no. of recruits 


\section{Community structure}

In 2008 (when 9 of the sites were surveyed) the benthic community in the back reef consisted of patch reefs and isolated coral bommies scattered over a bottom that was sandy, or a combination of sand and reef rock. The 9 sites were dominated by sand (6-68\% cover), CCA/bare space $(14-39 \%)$, and live coral $(8-43 \%)$. The live coral consisted mostly of Porites (6-30\% cover), Montipora $(0-27 \%)$ and Pocillopora $(0-6 \%)$, but there were also small amounts of Acropora $(\leq 0.2 \%)$, Gardineroseris $(\leq 0.2 \%)$, Leptastrea $(\leq 0.8 \%$ ), and Pavona ( $\leq 0.6 \%$ ) (Fig. 5). The 9 sites differed in cover of coral $(F=4.313$, $\mathrm{df}=8,171, \mathrm{p}<0.001)$ and sand $(F=8.122$, $\mathrm{df}=8,171, \mathrm{p}<0.001)$, but not CCA/bare space $(F=1.725, \mathrm{df}=8,171, \mathrm{p}=0.096)$. Percent cover of the most common genera of corals all differed among sites: Porites $(F=$ $2.482, \mathrm{df}=8,171, \mathrm{p}=0.014)$, Montipora $(F=$ 19.964, $\mathrm{df}=8,171, \mathrm{p}<0.001$ ), and Pocillopora $(F=2.471, \mathrm{df}=8,171, \mathrm{p}=0.015)$.

When averaged by shore, the back reef was dominated by Porites, but on the southwest shore there was also a relatively large amount of Montipora (Fig. 6). Montipora cover on the southwest shore was upwardly biased by Site 7, which was at the northern end of this shore and characterized by $27 \%$ cover of this coral (Fig. 5). Acropora was only found at Site 5, where the mean cover of this genus was $<0.2 \%$, and overall, Acropora was virtually absent in the back reef of both shores in $2008(<0.04 \%)$. Although these sites were not censused for community structure between 2005 and 2007 when the settlement tiles were in position, nearby sites that were censused in 2006 also revealed low cover of Acropora. In these areas, $<5 \%$ of the quadrats $(n=400)$ contained Acropora, and in virtually all cases, only small colonies were found.

Pearson correlation analyses revealed that the density of coral recruits and coral cover at the family level was unrelated $(p>0.05)$ across the 9 sites. However, when the coral data were pooled among taxa, total recruitment was positively correlated with coral cover between September and January 2005/06 ( $\mathrm{r}=0.782, \mathrm{df}=7, \mathrm{p}<0.05)$, and between January and September 2007 ( $\mathrm{r}=$ $0.806, \mathrm{df}=7, \mathrm{p}<0.05)$, but coral cover was not significantly correlated with recruitment
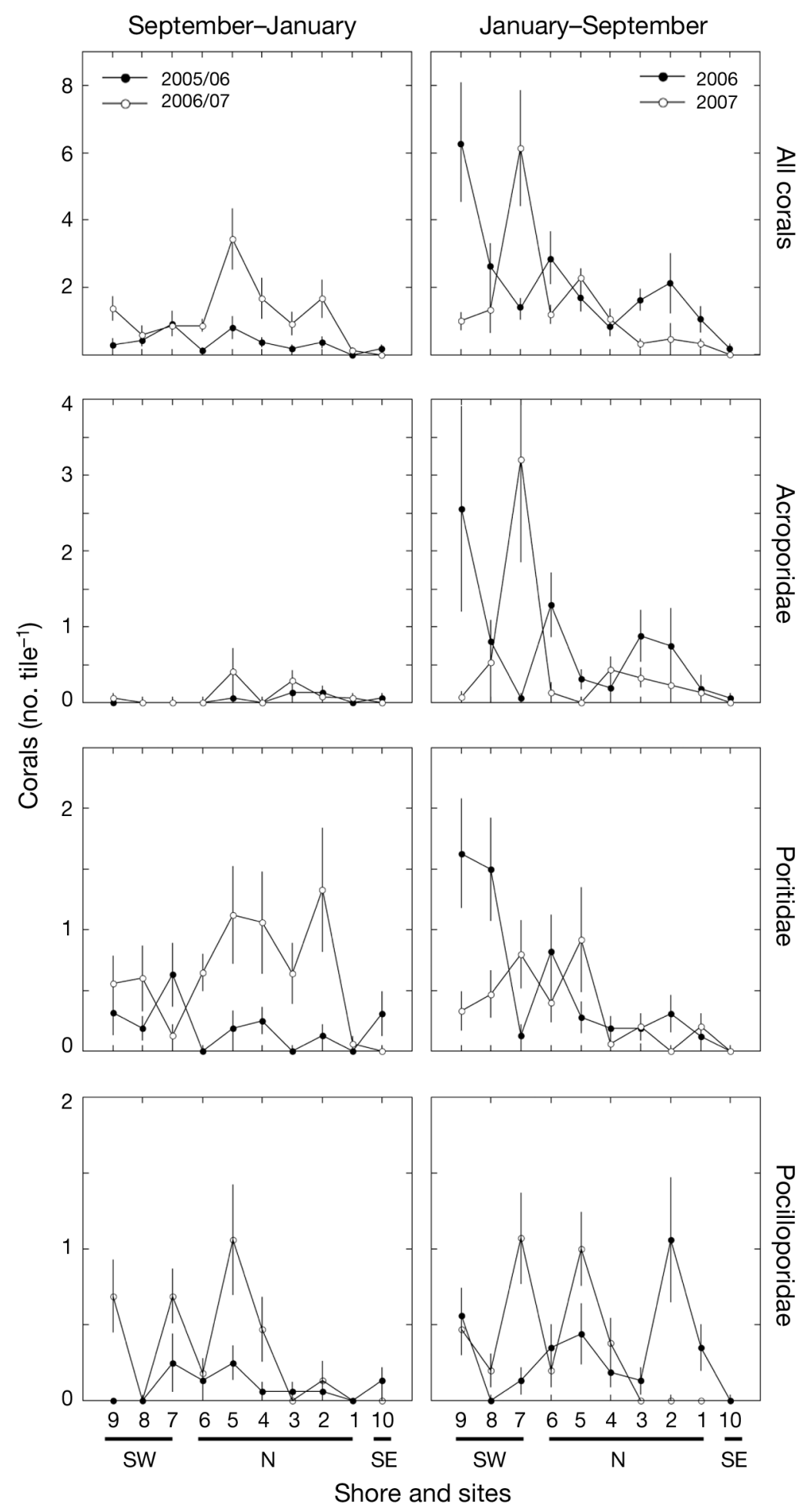

Fig. 4. Coral recruitment at 10 sites in the back reef of Moorea from September-January (left) and January-September (right), in 2005/06 and 2006/07. Results for all taxa pooled (All corals) and the 3 common families that were distinguished. Sites are organized from left to right to mirror their location clockwise from the most southern site on the southwest shore of Moorea (Fig. 1), with horizontal black bars showing sites located on the southwest (SW), north (N), and southeast (SE) shores, respectively. Data are means \pm SE based on 13-16 tiles site ${ }^{-1}$ 
Table 1. Results of 3-way ANOVA comparing the density of coral recruits (pooled among taxa; recruits tile ${ }^{-1}$ ) among sites (random), periods (fixed, September-January and January-September), and years (fixed, 2005/06 and 2006/07).

Data were transformed $(\sqrt{ }(x+3 / 8))$ prior to analysis

\begin{tabular}{|lcccc|}
\hline Source & MS & df & $F$ & $p$ \\
\hline Site & 3.612 & 9 & 11.957 & $<0.001$ \\
Period & 13.053 & 1 & 12.075 & 0.007 \\
Year & 0.268 & 1 & 0.210 & 0.658 \\
Site $\times$ Year & 1.277 & 9 & 4.228 & $<0.001$ \\
Year $\times$ Period & 8.896 & 1 & 5.397 & $<0.045$ \\
Period $\times$ Site & 1.081 & 9 & 3.578 & $<0.001$ \\
Site $\times$ Period $\times$ Year & 1.648 & 9 & 5.456 & $<0.001$ \\
Error & 0.302 & 588 & & \\
\hline
\end{tabular}

over the remaining 2 sampling periods $(\mathrm{p}>0.05)$. These tests of association involve coral cover measured the year after the recruitment surveys were completed; nonetheless, they suggest that there are combinations of conditions when coral recruitment is related to local coral abundance.

In contrast to the back reef, the fore reef on the north and southwest shores in 2006 contained large amounts of Acropora, with 4 to $12 \%$ cover at $10 \mathrm{~m}$ depth, and $5 \%$ cover at 17 m depth (Fig. 6). Porites was also well represented $(4-16 \%$ cover $)$, and there were lower amounts of Montipora (0.3-5\% cover). These data come from one site north of back reef Site 2, one west of Site 7, one $\sim 3 \mathrm{~km}$ east of back reef Site 1, and one $\sim 6 \mathrm{~km}$ southeast of Site 9. Extensive diving on the outer reef along the north and southwest shore in 2006 demonstrated that these study sites were representative of the coral community structure along each shore (P. J. Edmunds pers. obs.).

\section{Seawater temperature}

The local SST context for Moorea (as determined from the Advanced Very High Resolution Radiometer [AVHRR] satellite data; Fig. 2A) revealed a seasonal variation of $\sim 3^{\circ} \mathrm{C}$, with the coldest temperatures $\left(\sim 26.2^{\circ} \mathrm{C}\right)$ in August/September, and the warmest $\left(\sim 29.6^{\circ} \mathrm{C}\right)$ in December and April. The austral summer is the rainy season when periods of heavy clouds and torrential rain can cause substantial and rapid depressions of SST (e.g. January 2005 and 2007). The 2 periods sampled by the settlement tiles were superimposed on this seasonal variation, with the September to January deployment spanning the period of warming, and the January to September deployment spanning the period of consistent warm water followed by cooling (Fig. 2A). The seawater temperature at $\sim 2 \mathrm{~m}$ depth in the lagoon followed the same pattern of SST variation (Fig 2B), although temperatures were a little higher in the summer $\left(\sim 30.1^{\circ} \mathrm{C}\right)$ and subject to strong diurnal variation (Fig. 2C). The most extreme diurnal warming occurred between September and January, when differences as large as $3.4^{\circ} \mathrm{C}$ were recorded (e.g. Site 7), but diurnal variation $\geq 3.0^{\circ} \mathrm{C}$ was recorded in all periods.

When the seawater temperature records were truncated to sample a constant number of days in each sampling period, the records extended from 18 September to 15 January in 2005/06 and 2006/07, and from 30 January to 27 June in 2006 and 2007 (Fig. 7). The mean daily temperature varied among sites and years in both sampling periods, although it was warmer between January and June than between September and January. The variation in mean temperature among sites

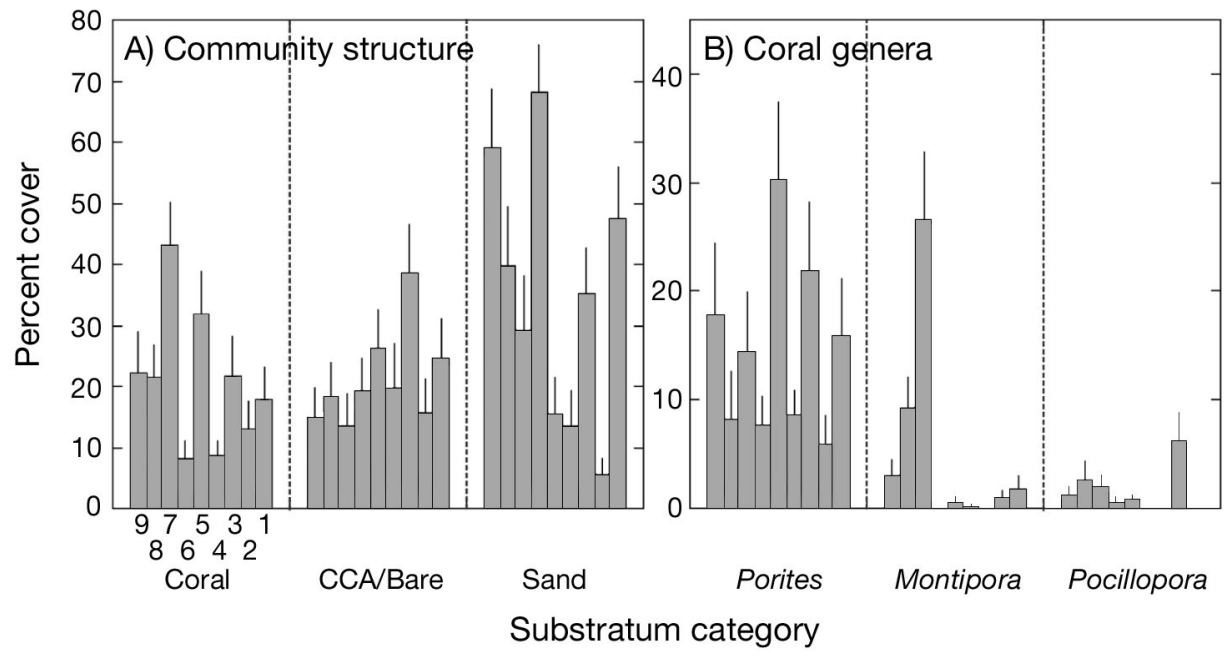

Fig. 5. Benthic community structure at 9 study sites in September 2007. (A) Major components of the community: Coral (live scleractinians), CCA/Bare (combined category of crustose coralline algae (CCA) and bare space), and sand. (B) Most abundant genera of corals. Values are means \pm SE ( $n=20$ quadrats); Bars: Sites 9-1, from left to right and numbered in Panel A (same for all categories). For location of sites see Fig. 1 
was more acute between September and January than between January and June, suggesting that there was an interaction between site and sampling period. Within each sampling period, among-site variation was similar in both years, suggesting there was no interaction between site and year. The daily range in temperature also varied among sites, but there was relatively little variation between years or sampling periods. The variation among sites in daily range in temperature appeared similar in both sampling periods and between both sampling years, suggesting that there was no interaction among these factors. Importantly, the apparent absence of a Site $\times$ Year interaction for the mean daily temperature and the daily range in temperature suggests that the site effects were repeatable among years (Fig. 7).

\section{Wave regime}

Both the magnitude and the seasonality of wave exposure varied among shores for Moorea. Wave exposure on the north shore, expressed as wave energy flux, reached peaks of $\sim 10$ to $40 \mathrm{~kW} \mathrm{~m}^{-1}$ in austral summer of each year and was low during the remainder of the year (Fig. 8). In contrast, wave exposure was greater on the southeast and southwest shores throughout the year. Peak wave energy flux (50 to $>100 \mathrm{~kW} \mathrm{~m}^{-1}$ ) occurred on the southwest shore in austral winter. Waves on the southeast and southwest shores were generally lowest during austral summer, but showed episodic periods of high energy throughout the year. In general, wave exposure was markedly higher on the southwest than on the north shore. Total wave energy summed over $20 \mathrm{~d}$ periods following the full moons in September, October, and November of each study year (Table 2) also showed large differences among shores. In general, wave power in these time periods was 2 to 5 fold greater on the southeast than the north shore, and up to 15 fold greater on the southwest than on the north shore.

\section{DISCUSSION}

The recruitment of animals with pelagic larvae in marine systems is intrinsically variable (Caley et al. 1996, Cowen \& Sponaugle 2009, Jones et al. 2009) and, therefore, it is unlikely that any single mechanism can fully explain variation in

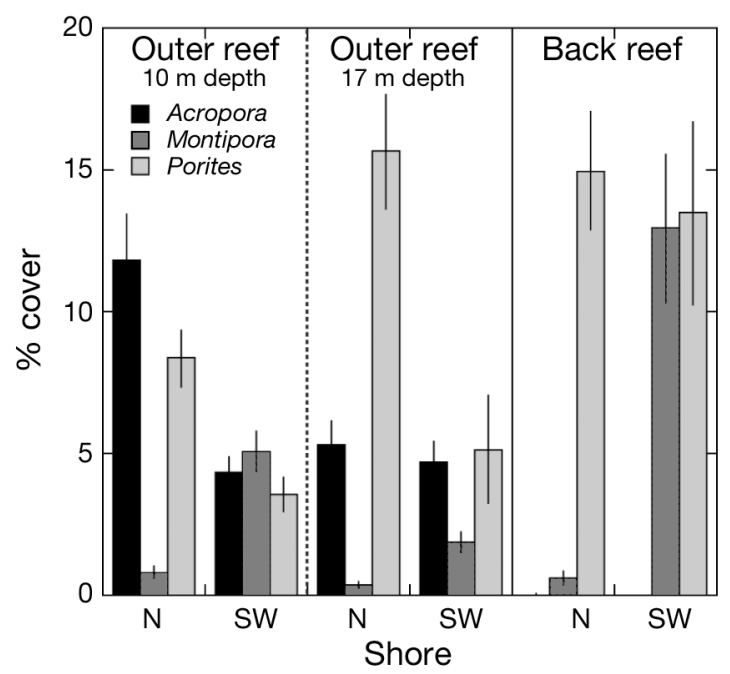

Fig. 6. Percentage cover of Acropora, Montipora, and Porites on the outer and back reef of the north $(\mathrm{N})$ and southwest (SW) shores of Moorea. Outer reef: data from 2006 and 2 sites per shore, monitored as part of the Moorea Coral Reef Long Term Ecological Research Site; Back reef: data from 2008, 6 sites on $\mathrm{N}$ and 3 on SW shores (see Fig. 1 for site locations). Data are mean $\pm \mathrm{SE}$ with sample sizes of 77-80 quadrats per shore/depth combination on the outer reef, 120 quadrats for $\mathrm{N}$ shore back reef, and 60 quadrats for SW shore back reef

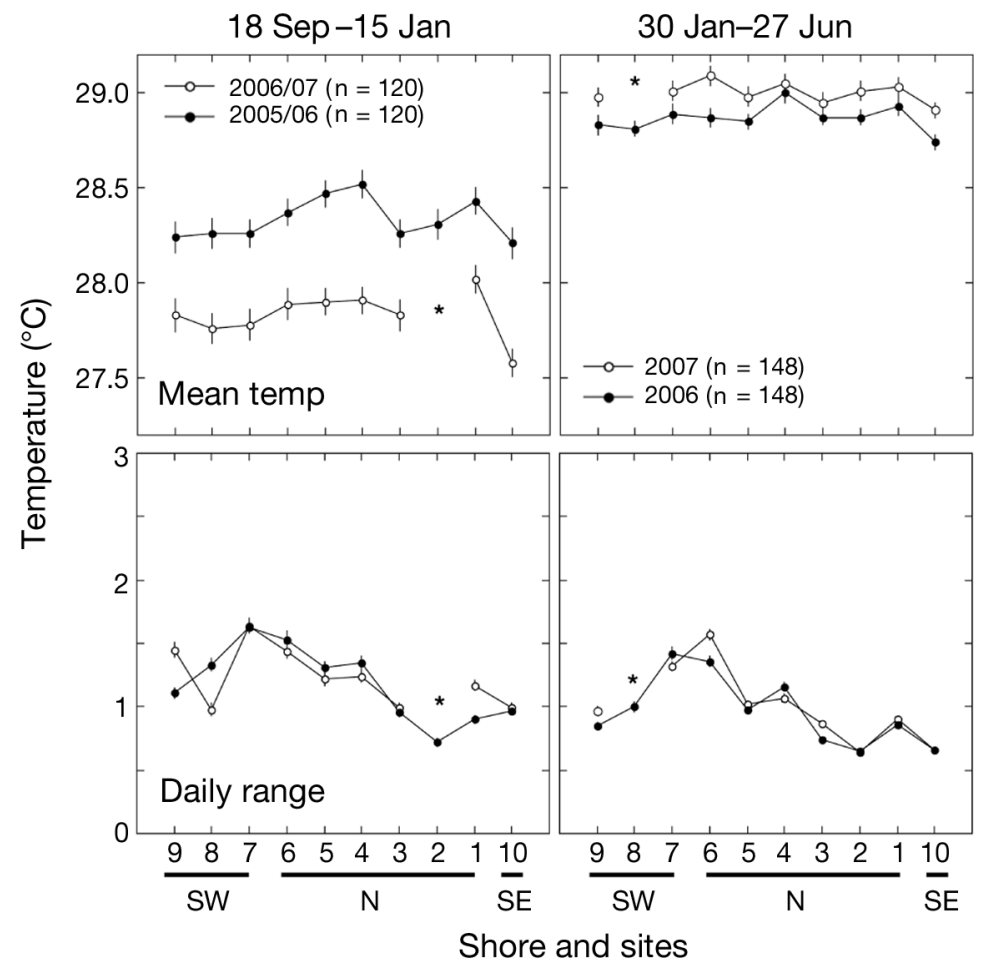

Fig. 7. Seawater temperature at 10 sites around Moorea (arranged on the abscissa as in Fig. 4) for the 4 sampling periods from September 2005 to June 2007. Upper panels: daily mean temperature (temp); Lower panels: mean daily range (daytime high-nighttime low) \pm SE. n: no. of daily records; $*$ : missing data due to logger failure 


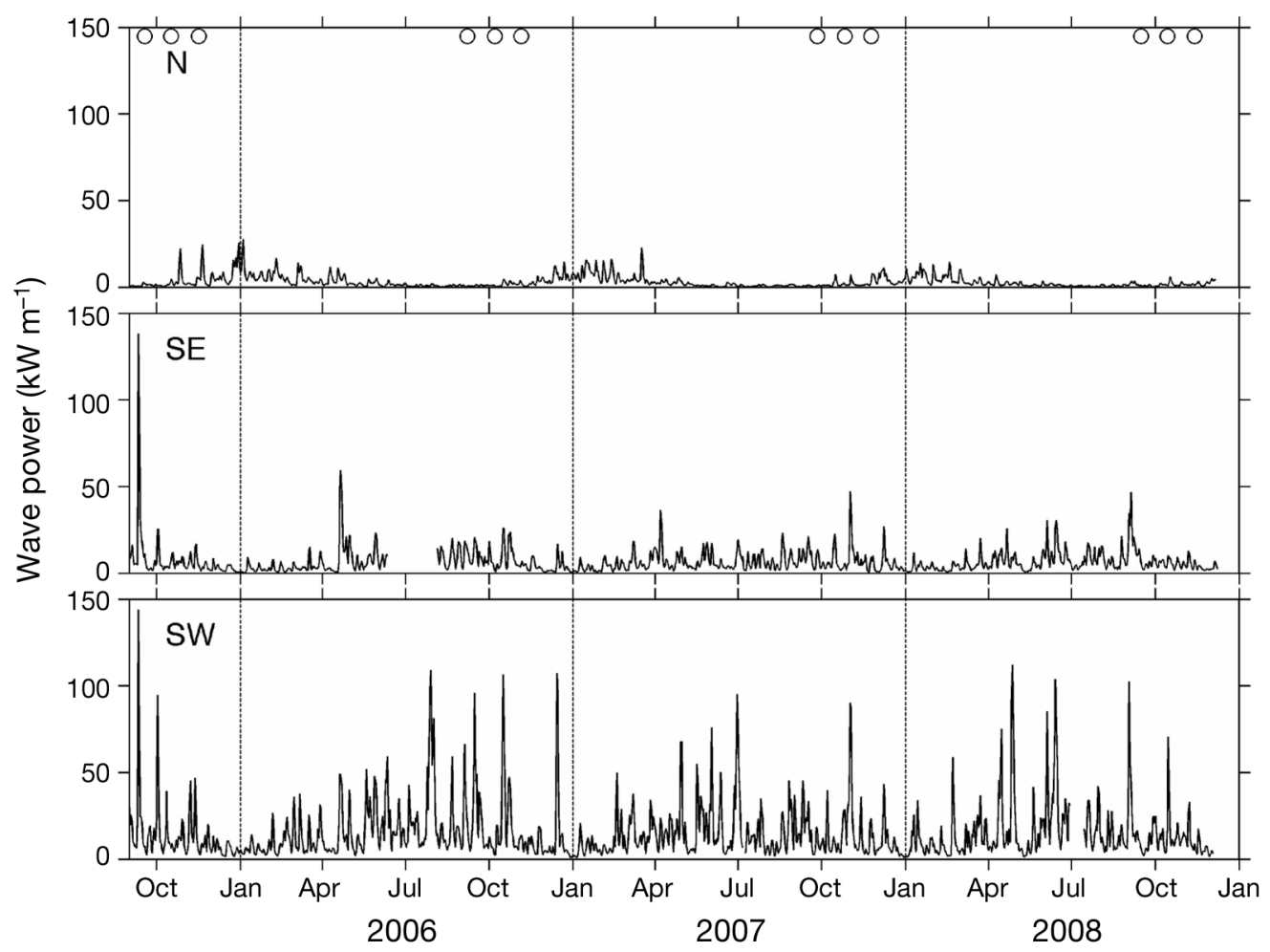

Fig. 8. Daily average wave power expressed as wave energy flux $\left(\mathrm{kW} \mathrm{m}^{-1}\right)$ for the north $(\mathrm{N}$, top panel), southeast (SE, middle panel) and the southwest (SW, lower panel) shores of Moorea, Sep 2005-Nov 2008. O: dates of the full moons in September, October, and November of each year; 12 species of Acropora have been reported to broadcast spawn gametes 5 to 13 nights after these full moons in Moorea (Carroll et al. 2006)

recruitment over space and time (Cowen \& Sponaugle 2009, Jones et al. 2009). Notwithstanding the experimental challenges that this creates, our results from Moorea are consistent with the hypothesis that amongsite variability in coral recruitment is influenced by the interaction of the offshore wave climate, the timing of coral reproduction, coral distribution, and the compass

Table 2. Total daily wave power $\left(\mathrm{kW} \mathrm{m}^{-1}\right)$ incident on the north, southeast, and southwest shores of Moorea summed over $20 \mathrm{~d}$ periods following the full moons in September, October, and November of 2005, 2006, and 2007

\begin{tabular}{|c|c|c|c|}
\hline \multirow{2}{*}{ Date } & 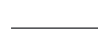 & - Shore - & \multirow[b]{2}{*}{ Southwest } \\
\hline & North & Southeast & \\
\hline \multicolumn{4}{|l|}{2005} \\
\hline September & 26 & 134 & 345 \\
\hline October & 90 & 121 & 185 \\
\hline November & 119 & 70 & 161 \\
\hline \multicolumn{4}{|l|}{2006} \\
\hline September & 19 & 195 & 513 \\
\hline October & 38 & 215 & 576 \\
\hline November & 40 & 94 & 167 \\
\hline \multicolumn{4}{|l|}{2007} \\
\hline September & 25 & 144 & 207 \\
\hline October & 37 & 220 & 489 \\
\hline November & 125 & 130 & 249 \\
\hline
\end{tabular}

orientation of the shore along which corals are recruiting. Our results provide an example of complex biophysical coupling involving coral reproduction, community structure, wave-induced transport processes, and recruitment. Given the widespread occurrence among marine organisms of pelagic larvae (Cowen \& Sponaugle 2009) and strong reproductive synchronization (Morgan \& Christy 1994), and the common occurrence of cross-reef transport of seawater on coral reefs (e.g. American Samoa, Smith \& Birkeland 2007; Jamaica, Genovese \& Witman 2004; Miyako Island, Kraines et al. 1998; and Hawaii, Storlazzi et al. 2004), it is likely that the putative biophysical coupling described here for Moorea has general application to a wider selection of organisms and other tropical reefs.

In Moorea, when seawater is warming between September and January, coral recruitment is elevated on the north shore due predominantly to settlement of poritids. Throughout this period, we suspect that the settlement of coral larvae in the back reef is promoted by enhanced retention arising from the slow cross-reef transport of seawater associated with small offshore waves (Hench et al. 2008). Even though powerful waves continue to drive cross-reef transport along the southwest shore from September to January, recruitment is lower in this location than it is between Janu- 
ary and September, probably because fewer competent coral larvae are available in outer reef seawater for transport. In contrast, between January and September when the temperature of seawater is high, but declining, and southerly wave exposure intensified, coral recruitment is elevated on the southwest shore by larger numbers of acroporids and poritids. As acroporids typically mass spawn in the warmest months (Harrison et al. 1984, Carroll et al. 2006), and were common on the outer reef of Moorea when this study was conducted (Adjeroud et al. 2009, P. J. Edmunds unpubl. data), we hypothesize that the approximate coincidence of wave-forced, cross-reef transport and acroporid reproduction produces elevated recruitment along the southwest shore. Thus, the back reef of Moorea is affected by seasonally variable cross-reef transport of offshore water (Hench et al. 2008), which transports zooplankters over the reef crest and into the lagoon (Alldredge \& King 2009). This flow would also transport coral larvae when coral reproduction is coincident with powerful waves, and influence thermal heterogeneity within the back reef as cross-reef transport varies in intensity. Although we did not measure the transport of coral larvae across the reef crest and, in fact, coral larvae were not found in one recent study that assessed the flux of zooplankton across the reef crest in Moorea (Alldredge \& King 2009), the presence of juvenile colonies of outer reef corals (e.g. Pocillopora eydouxi and Astreopora myriophthalma) behind the reef crest in some locations suggests that the delicate coral larvae can pass over the reef crest, settle, and grow into new recruits (P. J. Edmunds pers. obs.).

The rates of coral recruitment reported here, as well as the taxonomic composition of the recruits, are similar to those reported previously from Moorea. Our results show that corals recruited in the back reef at mean densities as high as 124 recruits $\mathrm{m}^{-2}$ (i.e. 6.31 recruits tile ${ }^{-1}$ ) over 5 to $7 \mathrm{mo}$, with higher recruitment between January and September when the water was warmest. We observed year-round recruitment of poritids, and higher representation of acroporids and pocilloporids in warmer compared to cooler months. In one of the 2 previous studies from this location, Adjeroud et al. (2007) reported recruitment of 21 to 345 corals $\mathrm{m}^{-2} \mathrm{yr}^{-1}$ on the outer reef, with the recruits dominated by pocilloporids, poritids, and acroporids; this early study was conducted over a 2 yr period beginning in December 2000. Pocilloporids and acroporids were most common during the warmest months, whereas poritids were common throughout the year (Adjeroud et al. 2007). On the outer reef, Adjeroud et al. (2007) reported that acroporids were at times a more significant fraction (i.e. up to $66 \%$ ) of the recruiting corals between September and December than was seen at any time in the present study. In the back reef, however, acroporids were more common between January and September $(\sim 34 \%)$ in the present study than during equivalent periods sampled by Adjeroud et al. (2007) on the outer reef (where acroporids represented $<16 \%$ of the recruits). Ten years prior to the fieldwork described by Adjeroud et al. (2007), between August 1990 and August 1993, Gleason (1996) recorded recruitment of 38 to 125 corals $\mathrm{m}^{-2}$ $\mathrm{yr}^{-1}$, with recruitment in the back reef $46 \%$ higher than on the outer reef, and dominated by acroporids, pocilloporids, and poritids. Acroporids and pocilloporids were most common in the warmest months (January to September), and poritids were found throughout the year, but with elevated densities between August and September (Gleason 1996).

Studies of coral recruitment encounter spatiotemporal variation on almost every scale investigated. For instance, the density of coral recruits varies between upper and lower surfaces of settlement tiles (Mundy 2000), among tiles within a cluster of tiles, sites within a habitat, habitats on a reef, and reefs with a region (Fisk \& Harriott 1990, Gleason 1996, Dunstan \& Johnson 1998, Hughes et al. 1999, 2000, Adjeroud et al. 2007, and many more). Further, the density of recruits varies among seasons and years (Banks \& Harriott 1996, Harriott 1999, Dunstan \& Johnson 1998), and the dominant genera recruiting can vary among seasons, sometimes years, and also between regions (Gleason 1996, Harriott 1999, Dunstan \& Johnson 1998, Adjeroud et al. 2007). Such variation has long intrigued biologists seeking to understand the relationship between recruitment and population structure (Caley et al. 1996, Morgan 2001, Cowen \& Sponaugle 2009), although this task has proved challenging in many marine systems where propagules have the potential to originate from (and travel to) a wide variety of locations (Caley et al. 1996, Cowen \& Sponaugle 2009), and populations are structured through a diversity of pre- and post- settlement events (Grosberg \& Levitan 1992, Caley et al. 1996, Hunt \& Sheibling 1997). In addition, the potentially long life span of coral colonies implies that rare and episodic recruitment may be sufficient to maintain adult coral populations (Warner \& Chesson 1985). Nevertheless, advances have been made in understanding why coral recruitment varies over space and time, with some of the causes attributed to the choice by larvae of cryptic locations to avoid competition with algae (Birkeland et al. 1981), the selection of CCA as cues for suitable settlement locations (Harrington et al. 2004), and the preference of larvae for certain wavelengths of light (Mundy \& Babcock 1998). Variation in the regional assemblage of coral species can also determine which taxa of coral larvae are available to settle (Harriott \& Banks 1995). 
Coral recruitment is also affected by a diversity of processes acting in concert to create outcomes that may appear idiosyncratic and inconsistent with a single mechanism. The leading causes of such variation are differential larval dispersal associated with life history strategies (Harrison \& Wallace 1990), coral cover (Connell et al. 1997, Vermeij 2005), the fecundity of adult corals (Hughes et al. 1999, 2000), temperaturemediated larval development and settlement (Edmunds et al. 2001, Putnam et al. 2008), hydrodynamic larval delivery (Jones et al. 2009), and pre- and postsettlement events (Dunstan \& Johnson 1998, Vermeij et al. 2006, Vermeij \& Sandin 2008, Penin et al. 2010). Life history strategy can have strong effects on coral recruitment, because the larvae originating from brooding versus broadcasting reproductive modes generally have dissimilar capacities for rapid settlement (e.g. Richmond 1987, Carlon \& Olson 1993, Graham et al. 2008), with brooded larvae potentially traveling short distances and settling close to the parents (Vermeij \& Sandin 2008). The dispersal of coral larvae is dependent on seawater flow, with eddies promoting retention on natal reefs (i.e. self-seeding; Black 1993), directional currents delivering larvae to downstream locations (van Oppen et al. 2008), and wave-driven flows delivering larvae to individual reefs or lagoons (Monismith 2007, Hench et al. 2008). The extent to which seawater motion can effect coral recruitment depends, however, on the coincidence of seawater transport with the availability of gametes and larvae. A clear example of this effect has been reported on the Great Barrier Reef, where the distribution of fecund Acropora spp. colonies explained up to $72 \%$ of the large-scale variation in Acropora recruitment across $1800 \mathrm{~km}$ of the reef tract (Hughes et al. 1999, 2000); in this case, propagule availability better explained coral recruitment than hydrodynamic variation alone.

To what extent can temperature and cross-reef flow explain the variation in coral recruitment in Moorea? First, the results of this study provide little support for the role of seawater temperature as a factor driving differential recruitment within the back reef. Both the variation among sites in mean daily temperature $\left(<0.4^{\circ} \mathrm{C}\right)$, and the daily range in temperature $\left(<0.9^{\circ} \mathrm{C}\right)$, have magnitudes that are unlikely to be of biological significance, and the tests of association between temperature and recruitment generated only one significant (but weak) result, specifically for pocilloporid recruits and the daily range in temperature $\left(r^{2}=0.26, p<0.05\right)$. Second, most of the corals in Moorea reproduce by broadcast spawning, including Acropora, Montipora, massive Porites, and all Pocillopora except for P. damicornis (Carroll et al. 2006, Adjeroud et al. 2007), and therefore, the distribution of brooding corals-and the larvae with short pelagic durations they tend to produce-is unlikely to be a fac- tor determining spatial variation in coral recruitment in this habitat. In contrast, coral recruitment in the back reef of Moorea is likely to be more characteristic of an open system (Caley et al. 1996, Cowen \& Sponaugle 2009, Jones et al. 2009), with many broadcast-spawning corals and a propensity for rapid seawater flushing. This assertion is consistent with the absence of a relationship between coral recruitment and coral cover at the family level, although overall coral recruitment (i.e. pooled among taxa) was positively related to overall coral cover in 2 of the sampling periods (September to January 2005/06, and January to September 2007). Under some conditions, it seems that coral colonies can enhance coral settlement, perhaps in ways that modify the hydrodynamic environment and favor larval retention. This possibility might account for the near-absence of coral recruits at Site 10, where the benthos was dominated by low-profile fields of rubble, which are not conducive to intercepting larvae as they are swept across the reef (Abelson \& Denny 1997). Although we cannot exclude the possibility that variation in coral recruitment in the back reef of Moorea is caused by differential fecundity of coral colonies (Hughes et al. 1999, 2000), the strength of this putative mechanism is degraded by the absence of strong physical gradients (e.g. in temperature) that could drive variation in fecundity, and rapid turnover of water in the lagoon and back reef (Hench et al. 2008).

Because coral community structure and seawater temperature cannot account for spatially variable coral recruitment in the back reef of Moorea, we hypothesize that the causal processes involve biophysical coupling among wave-driven flow across the reef, coral reproduction, and community structure. Although there are inconsistencies in recruitment between years that we attribute to the unpredictable confluences of larvae supply, hydrodynamic delivery, and the conditions favoring settlement and metamorphosis, in general, the amongsite variation in recruitment is similar between years for each sampling period, but consistently different between sampling periods. In Moorea, the strongest physical gradient that is coincident with the variation in coral recruitment is created by the wave climate. In this lowlatitude, central Pacific location, the wave climate is strongly affected by seasonal storms in distant locations. In the austral summer, long period swell (10 to $15 \mathrm{~s}$ ) with significant wave heights of 1 to $1.8 \mathrm{~m}$ impact the north shore of Moorea, and these are generated in the Northern Hemisphere; waves with shorter periods ( 8 to $10 \mathrm{~s})$ and reduced significant heights of 0.3 to $1.5 \mathrm{~m}$ are generated locally by the predominant trade winds, and these are evident throughout the remainder of the year. In the austral winter, storms in the Southern Ocean produce long period swell (up to $20 \mathrm{~s}$ ) and waves of exceptional height (up to $12 \mathrm{~m}$, significant wave heights of $\sim 3.3 \mathrm{~m}$ ) that impact southerly-facing shores, and at the same 
time, the north shore is prone to periods of calm caused by offshore Maraamu winds (Wolanski \& Delesalle 1995). Importantly, throughout the year, the wave power incident on the southwest shore is greater than that along the north shore (Fig. 8). One important consequence of this offshore wave climate is strong cross-reef transport of seawater that establishes local circulation, with seawater entering the back reef over the reef crest and exiting through passes in the reef (Hench et al. 2008). Although these circulation patterns in Moorea have only been studied on the north shore, they are also likely to be common on the southwest shore (J. J. Leichter pers. obs.). Such cross-reef circulation will vary seasonally in intensity in concert with the wave climate, and therefore would be strongest on the north shore in the austral summer and consistently strong on the southwest shore, with peak flows corresponding to the largest storms. Strong cross-reef transport establishes a number of bio-physical gradients of ecological importance: in the context of the present study, the most important is likely to be the advection of larvae into the lagoon from the outer reef.

For the scleractinian community of Moorea, the Acroporidae have a particularly strong potential to contribute propagules to wave-driven flow over the reef crest, because this taxon spawns large numbers of gametes in the warmest part of the year (Harrison et al. 1984, Carroll et al. 2006). Because this spawning event can be restricted to a short period (Harrison et al. 1984), the dispersal distances will be strongly dependent on the extent to which spawning coincides with periods of strong water motion, and this might be expected to vary greatly between years. In Moorea, one of the principal genera of this family (Acropora) had a spatially disjunct distribution when this study was conducted, because it was largely extirpated from the lagoon by bleaching in 1991 (Gleason 1993), yet covered 5 to $12 \%$ of the outer reef in 2006 (P. J. Edmunds unpubl. data). In the present study, the inability to distinguish recruits of Acropora from those of Montipora necessitated their collective scoring as acroporids, thereby making it impossible to distinguish the contribution of each genus to the recruitment of this family. Since Montipora were common at some of the lagoon sites (e.g. Site 7), this raises the possibility that acroporid recruitment could reflect the effects of Montipora larvae originating from corals in back reef, rather than from the outer reef. We feel this possibility is unlikely, however, because acroporid recruitment was not associated with the percentage cover of Montipora ( $\mathrm{r}<0.347$, $\mathrm{df}=7, \mathrm{p}=0.446$ ). Further, an origin of acroporid recruits on the southwest shore through the transport of larvae from the outer reef (described below) is a mechanism that can also be invoked to account for the distribution of poritid recruits along the same shore.
In Moorea, the reproductive biology of Acropora is incompletely known, but 12 Acropora species release gametes between October and November (Carroll et al. 2006). The spawning period for this genus probably extends over a longer period, since acroporids in Moorea recruit in large numbers from September to April (Gleason 1996, Adjeroud et al. 2007, present study). Thus, it is reasonable to infer that the heavy wave climate that impacts the southwest shore imports Acropora larvae into the back reef, which subsequently settle to tiles placed along this shore (i.e. Sites 7, 8, and 9). The period over which this mechanism could function is probably protracted, for not only is it likely that Acropora spp. spawn over multiple months, but in addition, anticyclonic motion of outer reef seawater creates the potential for multiple transgressions across the reef crest. While the offshore wave climate drives strong cross-reef transport of seawater in Moorea (Hench et al. 2008), an as-yet unknown mechanism causes a slow (mean speed of 2 to $4 \mathrm{~cm} \mathrm{~s}^{-1}$ ) anticyclonic flow around the island (L. Washburn pers. comm.), with each circumnavigation completed in 15 to $30 \mathrm{~d}$. Thus, Acropora gametes and larvae from the outer reef on the southwest shore could conceivably have multiple opportunities to be 'sampled' by repeated transgressions over the reef crest in this location. While such transgressions would also occur on other shores, the prevailing wave climate in the austral summer would ensure that the strongest transgressions occurred on the southerly shores. An effect similar to that described for Acropora might also function for poritids, which typically recruit in Moorea in the warmest months (Adjeroud et al. 2007), and in the present study were common on the southwest shore when temperatures were warm. We suspect that when stronger waves occur on the north shore between January and March, there are few competent Acropora larvae on the outer reef, and therefore cross-reef transport established at this time does not result in elevated acroporid recruitment at the north shore sites (1 to 6).

The biophysical coupling we hypothesize here between coral recruitment and reef-wide hydrodynamics has important implications for understanding the biological relationships between back reef and outer reef communities, both in Moorea and in other reef locations (e.g. Barshis et al. 2010). However, there are several important steps to be taken in order to test our hypothesis, and ultimately to determine whether it has general application. These steps should include detailed assays for fecundity (Hughes et al. 1999, 2000, Carroll et al. 2006) of coral colonies throughout the year, in multiple habitats and for multiple species, detailed hydrodynamic observations in the relevant habitats among shores followed by modeling of the transport of neutrally buoyant particles by cross-reef transport (Fiechter et al. 2008, Jones et al. 2009), and 
the application of population genetic tools (e.g. Baums et al. 2006, Barshis et al. 2010) to ascertain the degree of gene flow and relatedness between coral colonies and new recruits among habitats and sides of the island.

Acknowledgements. This research was supported by grant OCE 04-17412 from the National Science Foundation, gifts from the Gordon and Betty Moore Foundation, and support to J.J.L. from the SIO Associates; it was completed under a research permit issued by the French Polynesian Ministry of Research. We are grateful to N. Davies and the staff of the UC Berkeley, Richard B. Gump South Pacific Research Station for making our visits to Moorea productive and enjoyable, $\mathrm{M}$. Murray and K. Seydel for technical support, L. Washburn for sharing data and discussing wave and flow regimes in Moorea, and N. Colvard, N. Dallin, W. Goldenheim, D. Green, and N. Muehllehner for field assistance. The manuscript benefited from the comments of 3 anonymous reviewers. This is a contribution of the Moorea Coral Reef (MCR) LTER Site, and is contribution number 162 of the Marine Biology Program of California State University, Northridge.

\section{LITERATURE CITED}

Abelson A, Denny M (1997) Settlement of marine organisms in flow. Annu Rev Ecol Syst 28:317-339

- Adjeroud M, Penin L, Carroll A (2007) Spatio-temporal heterogeneity in coral recruitment around Moorea, French Polynesia: implications for population maintenance. J Exp Mar Biol Ecol 341:204-218

Adjeroud M, Michonneau F, Edmunds PJ, Chancerelle Y and others (2009) Recurrent disturbances, recovery trajectories, and resilience of coral assemblages on a South Central Pacific reef. Coral Reefs 28:775-780

Albright R, Mason B, Langdon C (2008) Effect of aragonite saturation state on settlement and post-settlement growth of Porites astreoides larvae. Coral Reefs 27:485-490

Alldredge AL, King JM (2009) Near-surface enrichment of zooplankton over a shallow back reef: implications for coral reef food webs. Coral Reefs 28:895-908

Bak RPM, Engel MS (1979) Distribution, abundance and survival of juvenile hermatypic corals (Scleractinia) and the importance of life history strategies in the parent coral community. Mar Biol 54:341-352

Banks SA, Harriott VJ (1996) Patterns of coral recruitment at Gneering Shoals, southeast Queensland, Australia. Coral Reefs 15:225-230

Barshis DJ, Stillman JH, Gates RD, Toonen RJ, Smith LW, Birkeland C (2010) Protein expression and genetic structure of the coral Porites lutea in an environmentally extreme Samoan back reef: Does host genotype limit phenotypic plasticity? Mol Ecol 19:1705-1720

Baums IB, Paris CB, Cherubin LM (2006) A bio-oceanographic filter to larval dispersal in a reef-buiding coral. Limnol Oceanogr 51:1969-1981

Best BA, Resing JM (1987) Active settlement of coral planulae: the effect of flow and swimming behavior on local recruitment. Am Zool 127:103A

Birkeland C, Rowley D, Randall RH (1981) Coral recruitment patterns at Guam. Proc 4th Int Coral Reef Symp 2:339-344

- Black KP (1993) The relative importance of local retention and inter-reef dispersal of neutrally buoyant material on coral reefs. Coral Reefs 12:43-53

Caley MJ, Carr MH, Hixon MA, Hughes TP, Jones GP,
Menge BA (1996) Recruitment and the local dynamics of open marine populations. Annu Rev Ecol Syst 27:477-500

Carlon DB, Olson RR (1993) Larval dispersal distance as an explanation for adult spatial pattern in two Caribbean reef corals. J Exp Mar Biol Ecol 173:247-263

Carroll A, Harrison P, Adjeroud M (2006) Sexual reproduction of Acropora reef corals at Moorea, French Polynesia. Coral Reefs 25:93-97

Chiappone M, Sullivan KM (1996) Distribution, abundance and species composition of juvenile scleractinian corals in the Florida reef tract. Bull Mar Sci 58:555-569

- Connell JH, Hughes TP, Wallace CC (1997) A 30-year study of coral abundance, recruitment, and disturbance at several scales in space and time. Ecol Monogr 67:461-488

Cowen RK (2002) Oceanographic influences on larval dispersal and retention and their consequences for population connection. In: Sale PF (ed) Coral reef fishes: dynamics and diversity in a complex ecosystem. Academic Press, New York, NY, p 149-170

> Cowen RK, Sponaugle S (2009) Larval dispersal and marine population connectivity. Annu Rev Mar Sci 1:443-466

Dean RG, Dalrymple RA (1991) Water wave mechanics for engineers and scientists. Advanced series on ocean engineering. 2. World Scientific, Singapore

> Done TJ, Dayton PK, Dayton AE, Steger R (1991) Regional and local variability in recovery of shallow coral communities: Moorea, French Polynesia, and central Great Barrier Reef. Coral Reefs 9:183-192

> Dunstan PK, Johnson CR (1998) Spatio-temporal variation in coral recruitment at different scales on Heron Reef, southern Great Barrier Reef. Coral Reefs 17:71-81

- Edmunds PJ (2000) Patterns in the distribution of juvenile corals and coral reef community structure in St. John, US Virgin Islands. Mar Ecol Prog Ser 202:113-124

Edmunds PJ, Gates RD, Gleason DF (2001) The biology of larvae from the reef coral Porites astreoides and their response to temperature disturbances. Mar Biol 139: 981-989

- Fiechter J, Haus BK, Melo N, Mooers CNK (2008) Physical processes impacting passive particle dispersal in the Upper Florida Keys. Contin Shelf Res 28:1261-1271

Fisk DA, Harriott VJ (1990) Spatial and temporal variation in coral recruitment on the Great Barrier Reef: implications for dispersal hypotheses. Mar Biol 107:485-490

Genovese SJ, Witman JD (2004) Wind-mediated diel variation in flow speed in a Jamaican back reef environment: effects on ecological processes. Bull Mar Sci 75:281-293

Gilmour JP, Smith LD, Brinkman RM (2009) Biannual spawning, rapid larval development and evidence of self seeding for scleractinian corals at an isolated system of reefs. Mar Biol 156:1297-1309

> Gleason MG (1993) Effects of disturbance on coral communities: bleaching in Moorea, French Polynesia. Coral Reefs 12:193-201

- Gleason MG (1996) Coral recruitment in Moorea, French Polynesia: the importance of patch type and temporal variation. J Exp Mar Biol Ecol 207:79-101

Graham EM, Baird AH, Connolly SR (2008) Survival dynamics of scleractinian coral larvae and implications for dispersal. Coral Reefs 27:529-539

> Grosberg RK, Levitan DR (1992) For adults only? Supply-side ecology and the history of larval biology. Trends Ecol Evol $7: 130-133$

> Harrington L, Fabricius K, De'ath G, Negri A (2004) Recognition and selection of settlement determine post-settlement survival in corals. Ecology 85:3428-3437

Harriott VJ (1999) Coral recruitment at a high latitude Pacific 
site: a comparison with Atlantic reefs. Bull Mar Sci 65:881-891

Harriott VJ, Banks SA (1995) Recruitment of scleractinian corals in the Solitary Islands Marine Reserve, a high latitude coral-dominated community in Eastern Australia. Mar Ecol Prog Ser 123:155-161

> Harriott VJ, Fisk DA (1987) A comparison of settlement plate types for experiments on the recruitment of scleractinian corals. Mar Ecol Prog Ser 37:201-208

Harrison PL, Wallace CC (1990) Reproduction, dispersal and recruitment of scleractinian corals. In: Dubinsky Z (ed) Ecosystems of the world, Vol 25. Coral Reefs. Elsevier, New York, NY, p 133-207

Harrison PL, Babcock RC, Bull GD, Oliver JK, Wallace CC, Willis BL (1984) Mass spawning in tropical reef corals. Science 223:1186119

Hench JL, Leihter JJ, Monismith SG (2008) Episodic circulation and exchange in a wave-driven coral reef and lagoon system. Limnol Oceanogr 53:2681-2694

> Hughes TP, Baird AH, Dinsdale EA, Moltschaniwskyj NA, Pratchett MS, Tanner JE, Willis BL (1999) Patterns of recruitment and abundance along the Great Barrier Reef. Nature 397:59-63

Hughes TP, Baird AH, Dinsdale EA, Moltschaniwskyj NA, Pratchett MS, Tanner JE, Willis BL (2000) Supply-side ecology works both ways: the link between benthic adults, fecundity, and larval recruits. Ecology 81:2241-2249

Hunt HL, Scheibling RE (1997) Role of early post-settlement mortality in recruitment of benthic marine invertebrates. Mar Ecol Prog Ser 155:269-301

Jones GP, Almany GR, Russ GR, Sale PF, Steneck RS, vanOppen MJH, Willis BL (2009) Larval retention and connectivity among populations of corals and reef fishes: history, advances and challenges. Coral Reefs 28:307-325

Kraines SB, Yanagi T, Isobe M, Komiyama H (1998) Windwave driven circulation on the coral reef at Bora Bay, Miyako Island. Coral Reefs 17:133-143

Levin LA (2006) Recent progress in understanding larval dispersal: new directions and digressions. Integr Comp Biol 46:282-297

> Miller K, Mundy C (2003) Rapid settlement in broadcast spawning corals: implications for larval dispersal. Coral Reefs 22:99-106

Monismith SG (2007) Hydrodynamics of coral reefs. Annu Rev Fluid Mech 39:37-55

Morgan SG (2001) The larval ecology of marine communities. In: Bertness MD, Gaines SD, Hay ME (eds) Marine community ecology. Sinauer Associates, Sunderland, MA, p 159-182

Morgan SG, Christy JH (1994) Plasticity, constraint, and optimality in reproductive timing. Ecology 75:2185-2203

Mundy CN (2000) An appraisal of methods used in coral recruitment studies. Coral Reefs 19:124-131

Mundy CN, Babcock RC (1998) Role of light intensity and spectral quality in coral settlement: implication for depthdependent settlement. J Exp Mar Biol Ecol 223:235-255

> Negri AP, Marshall PA, Heyward AJ (2007) Differing effects of thermal stress on coral fertilization and early embryogenesis in four Indo Pacific species. Coral Reefs 26: $759-763$

> Nozawa Y (2008) Micro-crevice structure enhances coral spat survivorship. J Exp Mar Biol Ecol 367:127-130

Penin L, Michonneau F, Baird AH, Connolly SR, Pratchett MS, Kayal M, Adjeround M (2010) Early post-settlement mortality and the structure of coral assemblages. Mar Ecol Prog Ser 408:55-64

Putnam HM, Edmunds PJ, Fan TY (2008) Effects of temperature on the settlement choice and photophysiology of larvae from the reef coral Stylophora pistillata. Biol Bull 215:135-142

Randall CJ, Szmant AM (2009) Elevated temperature reduces survivorship and settlement of the larvae of the Caribbean scleractinian coral, Favia fragum. Coral Reefs 28:537-545

Richmond RH (1987) Energetics, competency, and long-distance dispersal of planula larvae of the coral Pocillopora damicornis. Mar Biol 93:527-533

Sammarco PW, Andrews JC (1988) Localized dispersal and recruitment in Great Barrier Reef corals: the Helix experiment. Science 239:1422-1424

Smith LW, Birkeland C (2007) Effects of intermittent flow and irradiance level on back reef Porites corals at elevated seawater temperatures. J Exp Mar Biol Ecol 341:282-294

Storlazzi CD, Ogston AS, Bothner MH, Field ME, Presto MK (2004) Wave- and tidally-driven flow and sediment flux across a fringing coral reef: Southern Molokai, Hawaii. Contin Shelf Res 24:1397-1419

Szmant AM, Gassman NJ (1990) The effects of prolonged 'bleaching' on the tissue biomass and reproduction of the reef coral Montastrea annularis. Coral Reefs 8:217-224

Underwood JN, Smith LD, vanOppen MJH, Gilmour JP (2009) Ecologically relevant dispersal of coral on isolated reefs: implications for managing resilience. Ecol Appl 19:18-29

> van Oppen MJH, Lutz A, De'ath G, Peplow L, Kininmonth S (2008) Genetic traces of recent long-distance dispersal in a predominantly self-recruiting coral. PLoS ONE 3(10): e3401

van Woesik R (2010) Calm before the spawn: global coral spawning patterns are explained by regional wind fields. Proc R Soc B 277:715-722

van Woesik R, Lacharmoise F, Koksal S (2006) Annual cycles of solar insolation predict spawning times of Caribbean corals. Ecol Lett 9:390-398

- Vermeij MJA (2005) Substrate composition and adult distribution determine recruitment patterns in a Caribbean brooding coral. Mar Ecol Prog Ser 295:123-133

> Vermeij MJA, Sandin SA (2008) Density-dependent settlement and mortality structure the earliest life phases of a coral population. Ecology 89:1994-2004

Vermeij MJA, Fogarty ND, Miller MW (2006) Pelagic conditions affect larval behavior, survival, and settlement patterns in the Caribbean coral Montastraea faveolata. Mar Ecol Prog Ser 310:119-128

Vermeij MJA, Smith JE, Smith CM, Vega Thurber R, Sandin SA (2009) Survival and settlement success of coral planulae: independent and synergistic effects of macroalgae and microbes. Oecologia 159:325-336

> Warner RR, Chesson PL (1985) Coexistence mediated by recruitment fluctuations: a field guide to the storage effect. Am Nat 125:769-787

- Wolanski E, Delesalle B (1995) Wind-driven upwelling in Opunohu Bay, Moorea, French Polynesia. Estuar Coast Shelf Sci 40:57-66

Yeoh SR, Dai CF (2010) The production of sexual and asexual larvae within single broods of the scleractinian coral, Pocillopora damicornis. Mar Biol 157:351-359

Zar JH (2010) Biostatistical analysis. Prentice Hall, Englewood Cliffs, NJ

Submitted: January 21, 2010; Accepted: July 8, 2010

Proofs received from author(s): August 31, 2010
Editorial responsibility: Charles Birkeland,

Honolulu, Hawaii, USA 